\title{
Para cada um a sua verdade
}

\author{
Ana Campos
}

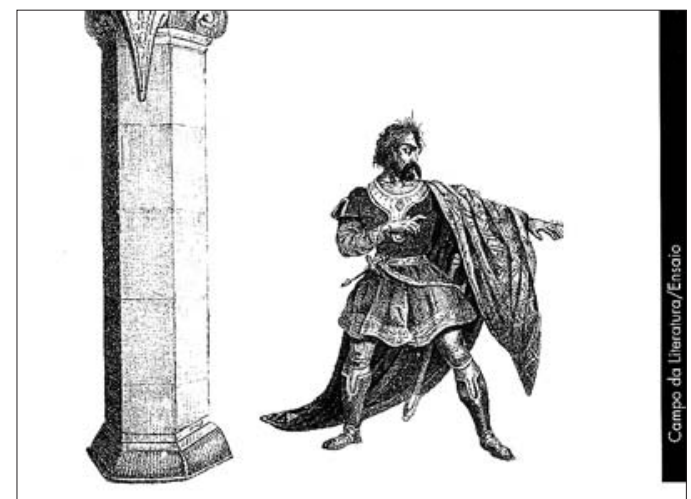

Jorge Bastos da Silva

\section{Shakespeare no Romantismo Português} Factos, problemas, interpretações

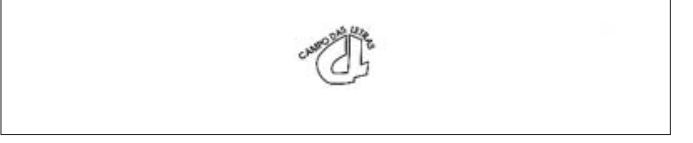

João Bastos da Silva neste seu livro traça, como o próprio título indica, as linhas dominantes da recepção de Shakespeare no Romantismo português, entendido este como o período que vai da década de 1830, marcada pelo fim do Portugal antigo e pela instauração da sociedade liberal, a meados da década de 1860, quando a jovem Geração de 70 impõe novas regras ao discurso intelectual dominante. Não são, portanto, exclusivamente literários, nem unicamente decorrentes da recepção de Shakespeare em Portugal os limites temporais estabelecidos.

Procura o autor, deste modo, fazer uma "sociologia da recepção" (p. 20) de Shakespeare em Portugal, ou seja, analisar os meios pelos quais a composição literária do dramaturgo isabelino chegou aos literatos portugueses do século XIX e o modo como foi por eles entendido e avaliado.

No que diz respeito a versões portuguesas - que 0 autor indica mas aqui não estuda em pormenor - registase a tradução de vários excertos, bem como versões completas de algumas das suas peças: Othello, por Simão de Melo Brandão, deixada em manuscrito (último quartel do séc. XVIII); 0 intrigante de Veneza, imitação de Othello de José Maria da Silva Leal (1842); Othello ou o mouro de
Jorge Bastos da Silva, Shakespeare no Romantismo português: Factos, problemas, interpretações, Porto, Campo das Letras, 2005, $331 \mathrm{pp}$.

Veneza, de Luis Augusto Rebello da Silva (1856); Sonho de uma noite de S. João, de António Feliciano de Castilho (1874); Hamlet (1877), O mercador de Veneza (1879), Ricardo III (1880), Othello, o Mouro de Veneza (1885), as quatro de D. Luís de Bragança (versões que muito contribuiram para suscitar o interesse pelo autor entre nós dada a importância do tradutor); Hamlet (1879) e O mercador de Veneza (1881), de Raimundo António de Bulhão Pato; Othello ou o mouro de Veneza (1881) e Hamlet (1887), de José António de Freitas, ambas acompanhadas de interessantes estudos críticos; Hamlet (1890), de João Félix Pereira; Rei Lear (1896), elaborado sobre a versão de Ducis, de José Maria da Costa e Silva, obra póstuma. 0 autor não deixa de realçar a estranheza desta escassez de traduções dada a importância do autor em Inglaterra desde o início do século XVIII, o apreço que Ihe votavam nomes como os de Scott e Byron tão apreciados entre nós, e ainda a sua divulgação em paises como a França e a Alemanha.

Não procedendo o autor a um levantamento dos espectáculos realizados em Portugal (e só pode lamentarse o desconhecimento que revela relativamente a uma fonte de informação como a CETbase - www.fl.ul.pt/centroestudos-teatro.htm), é para a referência a periódicos que recorre. Centra-se, assim, em primeiro lugar, em artigos publicados nos periódicos editados no exilio por intelectuais portugueses fortemente empenhados nas lutas liberais, em seguida em textos dados à estampa na imprensa portuguesa, posteriormente nas reflexões críticas mais alargadas dos principais pensadores do nosso século XIX, como António Feliciano de Castilho e Camilo Castelo Branco, entre outros, e, por fim, nas conferências proferidas em Lisboa e no Porto por Sheridan Knowles em 1845 sobre a obra do autor isabelino.

Um dado adquirido na análise da recepção de Shakespeare em Portugal durante o Romantismo é o de que a imagem que o público tinha deste autor era construída por via indirecta, quer através de versões sobretudo francesas, muito adulteradas em nome do decoro neoclássico, quer das óperas de temática shakespeariana, e não através do contacto directo com os dramas que efectivamente escreveu. As personagens e as obras surgem assim descaracterizadas, reduzidas a traços esquemáticos que, por vezes, se encontram tão afastados da sua essência que se chega a esquecer a sua origem. 
Temos, assim, um Shakespeare destituido do privilégio da organicidade ou da estrutura, um universo dramático descaracterizado, as obras como que desintegradas pela apropriação sumária dos seus elementos constituintes - e, portanto, na oportunidade de todas as excisões, deturpações, fraudes intelectuais e enganos involuntários. (p. 18).

Nos periódicos portugueses editados no exilio, eram sobretudo os assuntos políticos, militares e comerciais que dominavam, ficando relegadas para último lugar as questões literárias. São, contudo, excepções dois jornais: - Correio braziliense e 0 investigador portuguez em Inglaterra. 0 primeiro, a partir de meados de 1812, apresenta breves recensões (ou tão só referências sumárias) de obras inglesas recentemente editadas, noticiando a publicação, em inglês, das conferências dos irmãos Schlegel - August Wilhelm e Friedrich - que foram efectivamente importantes na canonização de Shakespeare. No entanto, estas alusões são tão breves que levam a duvidar que os redactores conhecessem realmente as obras que anotam. Curioso é também notar a quase ausência de menções aos mais importantes vultos da literatura inglesa de então como Wordsworth e Coleridge. Pelo seu lado, O investigador portuguez em Inglaterra, jornal politicamente concorrente do Correio, embora também remetesse para um plano secundário as questões literárias e culturais em geral, demonstrava um conhecimento mais aprofundado das obras, ocupando Pope e Milton um lugar de destaque. Interessantes para o estudo da recepção de Shakespeare em Portugal são as notícias da publicação de uma série de obras inglesas de e sobre o autor isabelino. Tal como acontecia com o Correio braziliense, os redactores não deixam transparecer um conhecimento directo destes textos. Entretanto, um projecto de um periódico intitulado 0 atheneu lusitano, de que se falava em 1816, onde seriam publicadas as mais importantes obras dramáticas europeias adaptadas aos palcos portuqueses, nunca veio a ser concretizado.

De entre os exilados mais ocupados com questões políticas destacava-se Garrett que, em 1822, considerava a barbaridade do teatro inglês incompativel com os nossos palcos, não deixando, no entanto, de reconhecer o mérito do poeta de Stratford-upon-Avon. Na sua vertente política, artigos vindos à estampa no periódico Paquete de Portugal - onde colaboravam nomes como os de Rodrigo da Fonseca Magalhães, Marco Pinto Soares Vaz Preto e José Liberato Freire de Carvalho -, usam passagens das obras de Shakespeare para ilustrar a defesa dos ideais liberais e antimiguelistas. É o caso de Macbeth para sinalizar o carácter usurpador da liderança de D. Miguel, a perversidade do seu carácter, bem como a sua dependência da rainhamãe e das suas cortesãs.

Na segunda parte do seu ensaio, o autor debruça-se sobre a imprensa periódica editada em Portugal. Aqui o cenário era diferente. Os jornais procuravam satisfazer as necessidades variadas de um público cada vez mais numeroso e diversificado. Emergem aí inúmeras formas de relacionamento com a obra do dramaturgo isabelino, quer sob a forma de textos literários originais ou traduzidos, quer na modalidade de recensões, ensaios, alusões, citações, bem como apreciações da obra do dramaturgo e de óperas de temática shakespeariana.

São, todavia, em número reduzido, os textos com carácter informativo sobre a vida e obra do autor, dos quais Jorge Bastos da Silva nos dá conta num interessante apêndice documental que inclui ainda os textos de reflexão crítica tratados na terceira parte do seu estudo. Aparecem com maior frequência os elogios e as alusões passageiras. É sintomático da falta de informação (e menos ainda de reflexão) sobre o dramaturgo que o tricentenário do nascimento do autor, em 1864, tenha sido quase ignorado entre nós, não Ihe chegando a fazer qualquer referência a ópera de Rossini apresentada em Dezembro desse ano no $\mathrm{S}$. Carlos, sem que, contudo, o autor indique as fontes a que acedeu na procura dessa informação.

É recorrente nos textos dos periódicos da época consultados, assinados por autores como Latino Coelho, Lopes de Mendonça, J. A. D. de Carvalho, Gustavo de Almeida entre outros, o que o autor considera um "débil carácter informativo (...) e fraca qualidade formativa" (p. 125), para lá de um apego - tardio e até certo ponto inconsistente com os ideais românticos - a "uma série de resistências e preconceitos, em geral devidos à persistência de noções criticas herdadas de uma corrente neo-clássica que entre nós demorou muito tempo a desaparecer" (Ibidem).

0 mais interessante artigo encontrado por Jorge Bastos da Silva foi publicado, em 1854, em A concórdia, jornal portuense, aliás, de pouco relevo. Ai é apresentado, em tradução, um texto espanhol, de autor não identificado, que recusa o anedotário sobre a vida do autor, que tenta distinguir textos genuínos de textos apócrifos e que procura falar da obra de Shakespeare no contexto histórico e literário em que foi produzida. Embora esta seja uma visão comum ao romantismo europeu, destaca-se, entre as opiniões recolhidas por Jorge Bastos da Silva, a apresentação do trabalho do dramaturgo isabelino como fruto de uma profunda reflexão que the permite atingir a verdade das figuras, legitimando-se, desta forma, o seu desrespeito pelas regras que, aliás, 0 autor anónimo afirma serem comuns a autores coetâneos como Jonson, Marlowe, Norton, Sackville, Beaumont e Fletcher, ou seja, insere Shakespeare numa linha que vem de Chaucer e Spenser. Este artigo aparece, assim, como uma resposta às censuras que recaíam sobre a obra de Shakespeare desde Voltaire, orientadas pelo gosto e pelo quadro teórico do classicismo.

Surgem ainda artigos que demonstram a familiaridade do público português com os grandes intérpretes shakespearianos como Garrick, Kemble, Talma e Kean e algumas alusões esparsas a dramas de Skakespeare representados entre nós. As referências às óperas, porém, são em geral meramente noticiosas ou apontamentos subjectivos do efeito do espectáculo no articulista. Curiosamente, é raro atribuir-se a matéria de certas óperas 
o

\section{Jnuestigator 非ortugue}

EM

INGLATERRA,

oU

J O R N A L

LITERARIO, POLITICO, \&C

vol. XXI.

Condo et compono, que max depromere passin.-HoR.

LONDRES:

IMPRESSO POR T. C. HANSARD

Na Offecina Portaguess,

1818.

\section{CORREIO BRAZILIENSE}

AR.M.AZEM IITER.ARIO.

voL. XXII.

LONDRES:

IMPRESSO POB R. GREENLAW, NA OFFCINA DO CORREIO

BRAZILIENSE, BECH STREET

1819 a Shakespeare, mas não podem estas ter deixado de servir de veículo de divulgação dos temas e das personagens do autor, criando curiosidade e expectativa entre o público.

É também interessante notar que os dramas de temática histórica não suscitaram grande atenção entre nós, no periodo analisado, numa época de tanto apreço pelo medievalismo. Subjacentes a este facto poderão estar motivos de ordem ideológica. Com efeito, o ideário absolutista e de direito divino da monarquia Tudor e Stuart - ao qual, no entanto, não podemos querer resumir o drama histórico shakespeariano - eram contrários ao novo espírito liberal.

Na terceira parte da sua obra, Jorge Bastos da Silva debruça-se sobre as opiniões críticas mais elaboradas como as assinadas por Tibúrcio Craveiro, António Feliciano de Castilho, Rebelo da Silva, Lopes de Mendonça, Latino Coelho, Mendes Leal e Camilo Castelo Branco, variando estas da maior adesão à mais séria resistência, fruto ainda de preconceitos neoclássicos que só com a Geração de 70 desapareceram. São exemplos da resistência ao elogio de Shakespeare a exigência que Tibúrcio Craveiro faz de que os heróis das tragédias fossem seres superiores, o que leva a inferir, embora o autor não o expresse abertamente, que os heróis de Shakespeare são demasiado humanos. No pólo oposto, Rebelo da Silva exalta no dramaturgo isabelino exactamente o modo impar como perscrutou a humanidade das figuras que concebeu. Activista político, fortemente ligado ao ideário socialista, Lopes de Mendonça adopta uma perspectiva política da literatura. Para ele os autores são fruto do seu tempo e da sua nação. Entende, assim, a história da literatura como reflexo da conjuntura política, vendo nos movimentos visando a democratização momentos de avanço da literatura, enquanto que os momentos de absolutismo surgem também no campo artístico como sendo de estagnação. E na sua clara apologia de Shakespeare e da Inglaterra (numa opção anglófila pouco comum nessa altura), considera-o "um génio criador, um génio tipo que fecha o círculo da Idade Média e abre com chave de ouro as portas ao mundo do individualismo, ao mundo da burguesia, ao mundo da indústria e do trabalho" (p. 148). É também uma ideia tipicamente romântica a veiculada por Camilo de que Shakespeare representa uma viragem na tomada de consciência da humanidade.

Por fim, o autor apresenta as conferências do dramaturgo irlandês James Sheridan Knowles, dadas em Maio de 1845, em Lisboa e no Porto, tendo como anfitrião e promotor Garrett, e que foram marcos importantes da recepção de Shakespeare no nosso país. Essas conferências analisaram, ao que se sabe ${ }^{1}$, o carácter paradoxal da obra do dramaturgo isabelino, a relação do seu génio artístico com a multiplicidade de figuras que criou, a realização teatral dos seus dramas e a sua recepção, tendo, no entanto, sido já esta temática abordada, talvez, de forma menos sistemática, por outros autores do nosso romantismo.

Ainda que incompleto, como o próprio autor reconhece, por não ter analisado todos os periódicos da época em estudo, nem apresentar o que já foi publicado sobre esta matéria, o ensaio de Jorge Bastos da Silva é um contributo válido para o estudo da recepção de Shakespeare em Portugal, devido à recolha documental a que procedeu (e cuja transcrição ocupa quase cem páginas do volume), às hipóteses de abordagem que sugere, aos problemas que levanta, às interpretações que faz. É, contudo, de lamentar que este ensaio não apresente uma conclusão onde sejam sistematizadas todas as ideias expostas no decurso do estudo. Esperemos que essa conclusão surja numa segunda obra, complementar desta, que o autor irá editar (como promete na p. 330), sobre as repercussões na literatura da recepção de Shakespeare no Romantismo português e a análise das suas traduções.
Os apontamentos de Sheridan Knowles, escritos entre 1820 e 1850 foram publicados postumamente, em 1873, com o titulo Lectures on Dramatic Literature Delivered by James Sheridan Knowles During the Years 1820-1850 (London, James McHenry, 1873) sem, no entanto, serem especificadas as datas das conferências a que correspondiam. 